\title{
Development of a flexible dialysis pore water sampler placement system: easy handling and related error sources
}

\author{
Stephan HILGERT, ${ }^{*}$ Friedrich GAUGER,,${ }^{1}$ Sebastian HÖLZLWIMMER, ${ }^{2}$ Stephan FUCHS ${ }^{1}$ \\ ${ }^{1}$ Institute for Water and River Basin Management, Department of Aquatic Environmental Engineering, Karlsruhe Institute of Technology \\ (KIT), Gotthard-Franz-Str. 3, 76131 Karlsruhe, Germany; ${ }^{2}$ Hochschule Weihenstephan-Triesdorf, University of Applied Sciences, \\ Department of General and Anorganic Chemistry, Environmental Analysis, Markgrafenstraße 16, 91746 Weidenbach, Germany \\ *Corresponding author: stephan.hilgert@kit.edu
}

\begin{abstract}
Investigations in the context of greenhouse gas production measurements in sub-tropical reservoirs brought up the necessity to survey the in situ pore water gas and ion concentrations at many positions within a relatively short time. As several sediment cores were taken, the interest in analysing the pore water at the same time and at the same positions forced us to develop a cost-and time saving method for the placement of dialysis pore water samplers (DPS). General prerequisites were the ability to place several DPS per day, within a flexible depth range of up to $40 \mathrm{~m}$ and with a low cost budget. To meet these requirements, a DPS placing system (DPSPS) was developed, which would allow the precise placement of DPS in water with a depth of up to $40 \mathrm{~m}$ and assessing the biases of on-board measurements and possible methodological improvements. The DPSPS was transported to Brazil and tested in a measurement campaign for 10 days. The measurements were carried out during two campaigns in December 2012 and March 2013 in the Capivari Reservoir north-east of Curitiba in the State of Paraná. The system worked properly and several DPS could be placed from a $5 \mathrm{~m}$ class aluminium boat. The placement was performed with high accuracy regarding the positioning as well as the penetration depth of the DPS. After the recovery of the DPS, the possible biases during sampling were analysed. Possible back-diffusion was investigated, taking oxygen concentration as one representative parameter for estimation of the sample behaviour. Laboratory as well as field results showed that special care has to be taken to minimize the influence of diffusion processes during post-recovery sampling. The results also suggested that the used membranes are affected by clogging which is likely to influence the diffusion times of various ions and gases. It can be stated that the DPSPS was developed successfully as the demands in terms of handling as well as monitoring efficiency and sample quality were met. With this deployment and measurement technique, a valuable part in the assessment of greenhouse gas emissions from surface water bodies could be achieved.
\end{abstract}

Key words: Placement system, sediment peeper, pore water, diffusion, DPS.

Received: July 2014. Accepted: November 2014.

\section{INTRODUCTION}

According to Teasdale et al. (1995), dialysis pore water samplers (DPS) bear a number of advantages with regard to bio-chemical sediment investigation. The DPS were adapted to and specialized for different purposes in the last decades (Hesslein, 1976; Lewandowski et al., 2002; Lewandowski et al., 2003; Thomas and Arthur, 2010; Schubert et al., 2011). The applications reach from the measurement of concentration gradients of heavy metals and redox conditions to the calculation of diffuse fluxes of gas from the sediment to the water body (Urban et al., 1997; Thomas and Arthur, 2010). Since DPS deliver valuable information about the biochemical processes and concentrations in almost undisturbed sediments, this sampling technique still has its place in modern environmental science. Based on the fact that most water bodies have an average depth much deeper than $2 \mathrm{~m}$, the manual placement of DPS either by wading or from a boat becomes impossible. Therefore, divers, submarines or gravity peep- ers are the only options for introduction of peepers in deeper areas of lakes or reservoirs. All of these options have severe disadvantages. Divers and submarines generally produce high costs and the entire placement procedure is time- demanding if extensive areas have to be covered. The use of DPS, which are brought into the sediment by gravity, falling vertically from a boat like a gravity coring system, has the drawback that their impact will most likely disrupt the sediment. In addition, the penetration depth and position details cannot be controlled. Both effects complicate acquisition of reliable data as the results become biased.

In addition to the placement efforts, the treatment of DPS before and after recovery is complicated and costly as the DPS have to be kept in oxygen-free atmosphere before placement and have to be analysed in a glove box afterwards (Teasdale et al., 1995; Dattagupta et al., 2007; Lyons et al., 1979). Addressing these major drawbacks of DPS, our intention was to develop a DPS placing system (DPSPS), which would allow the precise placement of 
DPS in water with a depth of up to $40 \mathrm{~m}$ and assessing the biases of on board measurements and possible methodological improvements. The DPSPS was designed not only to place one type of DPS, but should also be capable of placing DPS with variable chamber sizes and design factors. As mobility of equipment has become an important requirement, the DPSPS design should allow all components to fit in a single aluminium box making it transportable in airplanes. The system was tested with a set of eight peepers investigating gas concentrations and redox conditions in the sediment of mid-sized sub-tropical Brazilian reservoir. From pre-survey investigations, it could be assumed that the predominant sediment type found in the reservoir is a rather soft mixture of silt and clay. Measurements were carried out during two campaigns in December 2012 and March 2013.

\section{METHODS}

\section{Placement system concept and construction}

To avoid the utilization of divers or AUVs and still be able to have a fast workflow placing the peepers, an innovative placing system was developed. To keep the as- sembly as simple as possible, components are made from a rapid construction kit of prefabricated aluminium profiles resulting in a compact mechanism, which can be transported and used on a $5 \mathrm{~m}$ aluminium boat (Fig. 1).

The inside of the housing bears two pairs of guide rails on either side, made from polyethylene. These provide a robust and dirt-proof vertical guidance for two sleds, which are connected through a pull-eye mechanism, featuring a 1:2 translation. A hydraulic cylinder specified to max. $40 \mathrm{~cm}$ extension drives one sled upwards while the other sled is pulled downwards, resulting in an $80 \mathrm{~cm}$ travel of the peeper sled. Two foldable aluminium-framed PVC stands on both sides assure that the entire DPSPS keeps an upright position and does not sink into the sediment. The pressure for the sled movement comes from a manual hydraulic pump located on the boat. The pump and cable system is capable of delivering 200 bar maximum pressure equalling $500 \mathrm{~kg}$ down force of the peeper sled. With every stroke of the hand pump, the pressure in the cylinder increases and pushes the peeper deeper into the sediment. After applying approximately 80 bars, the peeper reaches the maximum depth and the previously adapted holding mechanism releases it at exactly the con-

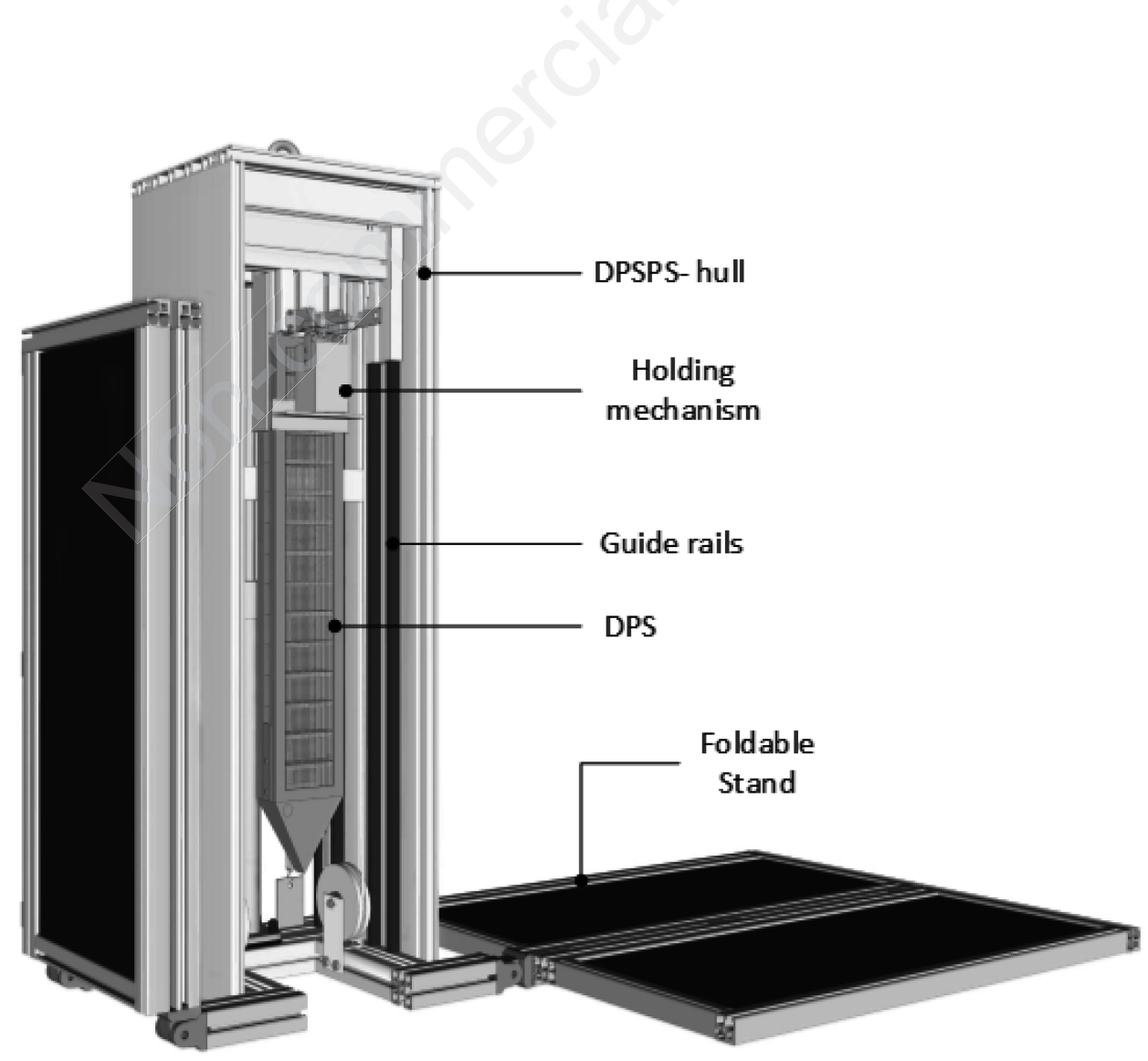

Fig. 1. Design of the dialysis pore water samplers placing system, showing one stand folded and one unfolded; design and construction by S. Hölzlwimmer. 
figured sediment depth. For harder sediment, a higher pressure is needed. Accordingly, the DPSPS can be equipped with additional weight to generate appropriate counter weight.

The DPS itself looks similar to former designs (Winfrey and Zeikus, 1977), but is made from 15 individual aluminium compartments assembled using a 2-component epoxy resin. 15 chambers for a length of $60 \mathrm{~cm}$ result in an effective vertical resolution of $4 \mathrm{~cm}$. On the bottom end, a stainless steel tip is bonded to the body allowing easy sediment penetration (Fig. 2).

Two closure frames bear a steel mesh protecting the inner membrane tubes. The peepers allow various membranes to be chosen according to specific measurement demands. The DPSPS is also capable of deploying peepers of various designs. The chamber size and therefore the depth resolution can be altered, as long as the outer dimensions of the peeper stay the same.

\section{Peeper preparations}

For the preparation of the DPS, a regenerated cellulose membrane tube (ZelluTrans; Carl Roth GmbH, Karlsruhe, Germany) with a molecular weight cut off (MWCO) between $1.99265 \times 10^{-23} \mathrm{~kg}$ and $2.32475 \times 10^{-23} \mathrm{~kg}$, which is equivalent to a pore size of $\sim 4 \mathrm{~nm}$ (US Environmental Protection Agency, 2005), and a thickness of $20 \mu \mathrm{m}$, was cut into segments of $10 \mathrm{~cm}$ length. Each of the segments was then filled with distilled water and closed at the end with polyamide 6.6 cable straps. Care was taken to avoid air bubbles inside the membrane tube and thus keep it as free of oxygen as possible. Each bag then contained a volume of $\sim 50 \mathrm{~mL}$. Shortly, before placement one bag was positioned inside each chamber of the DPS and the housing was closed securely with a polyamide 6.6 cable strap.

\section{Placing}

The prepared DPS was clamped in the DPSPS. The DPSPS was then lowered with the help of an electric winch until the tension in the steel cable lessened by the DPSPS reaching the sediment surface. The dialysis sampler was vertically pushed into the sediment by the handdriven hydraulic system. Finally, after pulling up the DPSPS, a buoy was attached to a rope connected to the peeper for marking the location of the peeper and for recovery at a later stage. The rope attached to the DPS and a buoy should always have the minimum rope length $(r l)$ (eq. 1) to secure that the placed DPS stays unaffected by wave action during storm events.

$r l=d+1+\ln (d)$

where $d$ is the water depth in $\mathrm{m}$ at the current position. If the water body is affected by rapid water level changes, like in reservoirs, the maximum water level at the current position should be used as $d$.

\section{Peeper recovery and sample treatment}

The peepers were recovered by pulling them out of the sediment and up to the surface using the ropes attached to the buoys. After the peeper was retrieved back on the boat, handling was to be conducted as fast as possible to prevent diffusion of oxygen into the membrane and methane to the atmosphere which would accordingly falsify sample analysis. For the whole sampling procedure
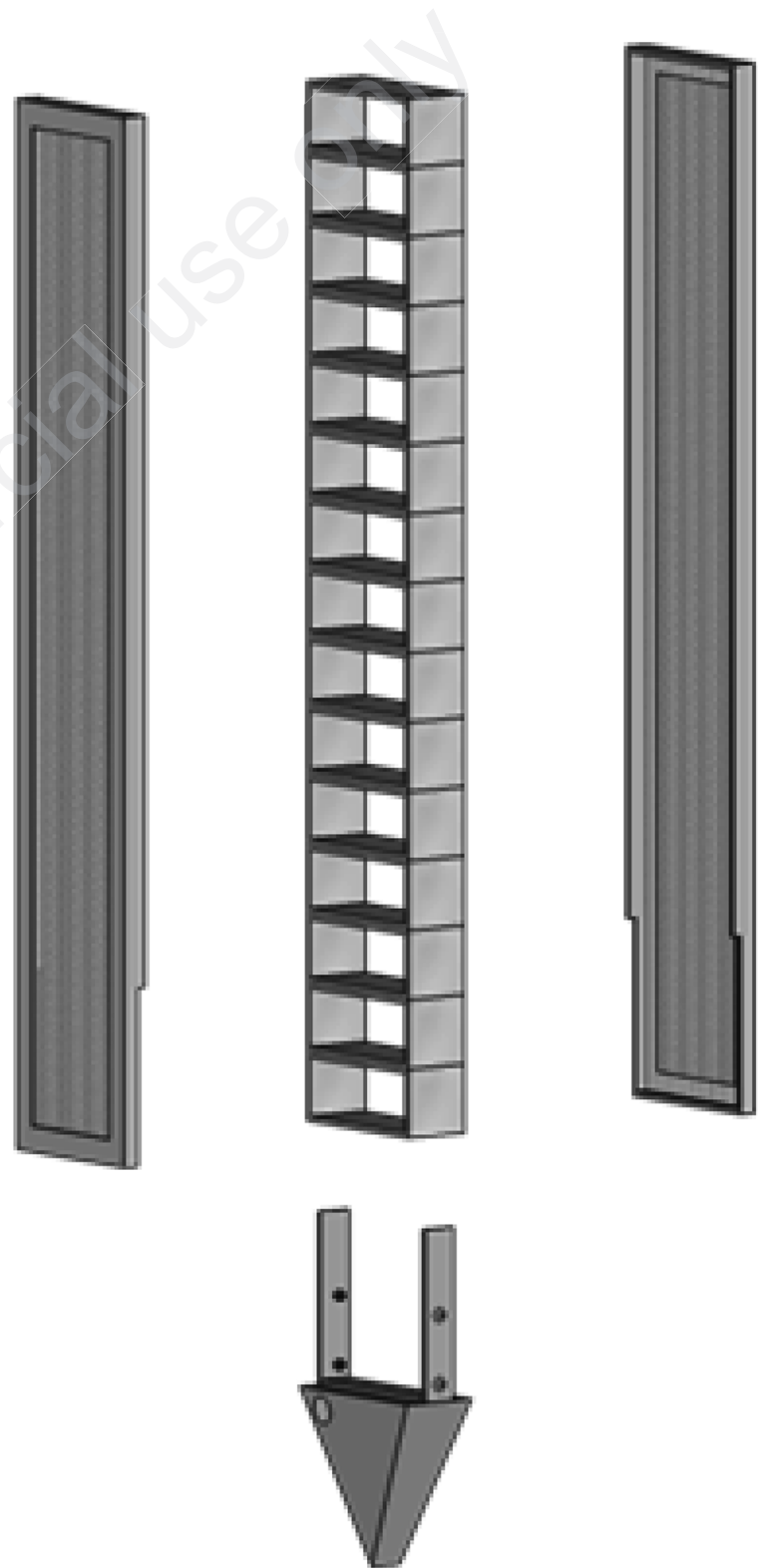

Fig. 2. Principal components of the dialysis pore water sampler; design and construction by F. Gauger. 
of 15 chambers, about $30 \mathrm{~min}$ were needed. The executed sampling sequence included photo documentation, in situ oxygen and temperature measurements, and headspace sampling for further analysis.

After recovery of each peeper, the first step was to take photos to document the position of the sediment water interface (SWI) marked by sediment adhesions on the peeper hull. Then, the cable straps were cut off and the DPS opened. Due to the highest expected gradients and hence the fastest diffusion, the oxygen concentration and temperature were measured beginning from chamber 15 (lowermost chamber) using a medical syringe sensor (Oxygen Microsensor; PreSens, Regensburg, Germany). The syringe has the benefit that the bag does not need to be opened and therefore air contact of the sample can be kept to the minimum. Before insertion of the syringe, the bags were cleaned of sediment particles to avoid bringing particles from the outer surface into the sampling solution. In the next step, a probe of $10 \mathrm{~mL}$ volume was taken with a syringe (Omnifix $10 \mathrm{~mL}$; Braun, Melsungen, Germany) fitted with a metal cannula (100 Sterican; Braun) from the membrane bag and transferred to a $20 \mathrm{~mL}$ headspace brown glass vial filled with ambient air. To let the air escape from the vial, a second cannula was placed in the rubber septum of the vial cap. To prevent degradation of methane through microorganisms, the vial was previously prepared with $0.1 \mathrm{~mL}$ of a preserving agent $\left(0.6 \% \mathrm{HgCl}_{2}\right.$ solution) (Bartram and Richard, 1996). For each sample, a fresh syringe was used and during all measurements, the membrane bags were kept away from direct sunlight. Vials were afterwards stored dark and cool at $4^{\circ} \mathrm{C}$ until analysis.

\section{Error control experiments}

Due to the disclaimed deoxygenation prior to the DPS placement, biased results could occur. Vice versa, after the recovery of the DPS, back diffusion to the membrane bags can alter the original concentration of oxygen sampled.

For measurement of the oxygen diffusion rate through the membrane exposed to air, a laboratory experiment was conducted. Eleven bags of the same membrane material, filled with air-saturated deionized water, were submerged in helium-stripped deoxygenated water. The gradient of oxygen concentration was then measured over time. After reaching a concentration of zero $\mathrm{mg} \mathrm{L}^{-1}$, four bags were exposed to ambient air and the rise of oxygen inside the bags was recorded analogously.

The results of the oxygen diffusion experiment show that the full equilibration of oxygen between two compartments, with a starting concentration of $8.65 \mathrm{mg} \mathrm{L}^{-1}$ inside the membrane, is reached after $340 \mathrm{~min}$, ending with a concentration of $0 \mathrm{mg} \mathrm{L}^{-1}$ (Fig. 3). Since the incubation time (eq. 2) and membrane retardation factor $\alpha_{M}^{W}$ [-] (eq. 3) can be calculated after Brandl and Hanselmann
(1991) and the permeation coefficient (eq. 4) after Crank and McFarlane (1981), it can be concluded that the diffusion through the membrane is slower than diffusion within the sediment. Therefore, the introduced DPS could not be expected to cause a measurable effect or artifact. Since the oxygen from the introduced DPS will be depleted after around six hours, this effect will be negligible after seven to nine days of deployment in an entirely anoxic environment.

$$
\begin{aligned}
& \mathrm{t}=\frac{\mathrm{F}}{2} \times \mathrm{k}^{-1} \times \ln \left(\frac{\mathrm{C}_{0}}{\mathrm{C}_{0}-\mathrm{C}_{\mathrm{i}}}\right) \\
& \alpha_{\mathrm{M}}^{\mathrm{W}}=\frac{\mathrm{D}_{\mathrm{w}}}{\mathrm{D}_{\mathrm{M}}} \\
& \mathrm{k}=\frac{\mathrm{F}}{2} \times \mathrm{t}_{\mathrm{d}}{ }^{-1} \times \ln \left(\frac{\mathrm{C}_{0}}{\mathrm{C}_{0}-\mathrm{C}_{\mathrm{i}(\mathrm{t})}}\right)
\end{aligned}
$$

where $t$ is the equilibration time, $F$ the design factor after Brandl and Hanselmann (1991), $t_{d}$ the time allowed for diffusion, and $C_{o}$ and $C_{i}$ the concentrations in the surrounding, respectively the water inside the sample bag. $D_{W}$ is the diffusion coefficient for water, being about 1.108 times higher than that of sediment, and $D_{m}$ the diffusion coefficient for the membrane of a single species. Derivation of the original formulas can be found in Brandl and Hanselmann (1991).

For the interpretation of on-boat oxygen measurement results from DPS, the second correction test is important (Fig. 4). After recovery of the DPS from anoxic sediments, one important source of biased results is the diffusion of oxygen back into the membrane bags. The diffusion of oxygen into the membrane happens faster if concentration differences are larger and decreases when concentrations inside and outside the

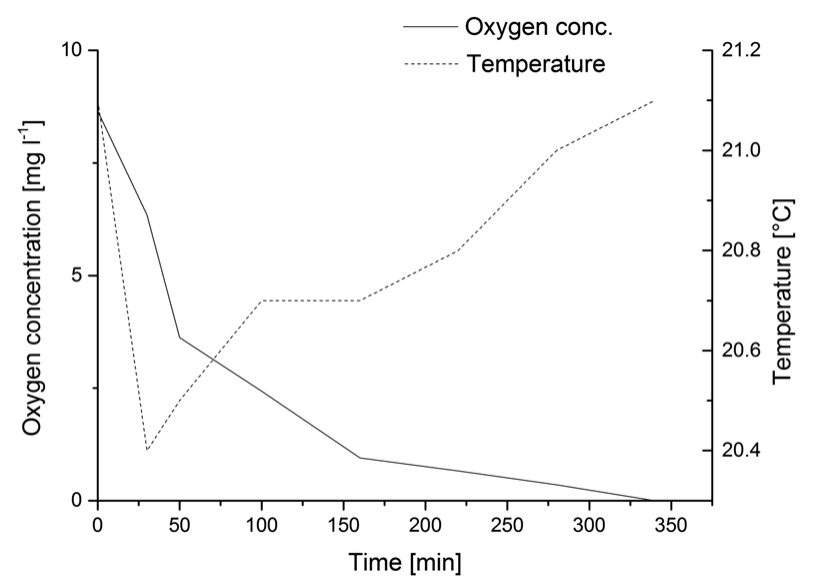

Fig. 3. Oxygen diffusion from membrane bags under zero-oxygen conditions. 
bag converge. These findings are in accordance with Brandl and Hanselmann (1991). Fig. 4 only shows the beginning phase of a stretched sigmoid-shape saturation curve as the experiment was stopped after around 35 min, which was the relevant time for the DPS-related on-board measurements.

\section{RESULTS AND DISCUSSION}

The DPSPS proofs to be transportable and easy to handle. It is capable of deploying DPS at a water depth between 2-40 $\mathrm{m}$. We can proceed on the assumption that the system can be easily modified to work in deeper reservoirs, as long as the flow velocity of the water body is low. The entire deployment procedure for one peeper took around $30 \mathrm{~min}$.

The results show that diffusion of oxygen actually happens fast. By comparison of the laboratory results with the measured values of oxygen at deployed DPS, it is indicated that the membrane gets less permeable after time in sediment. With a handling time of around $2 \mathrm{~min}$ for each sample bag in in-field analysis, the third bag should already show concentrations of oxygen at around $1 \mathrm{mg} \mathrm{L}^{-}$ ${ }^{1}$. However, as shown in Fig. 5 the measured concentrations of oxygen often stay at zero for more than $10 \mathrm{~min}$ (58-46 $\mathrm{cm}$ below SWI). This suggests that clogging through particles occurs at the used membrane as already observed by Brandl and Hanselmann (1991) and Jacobs (2002) with comparable membranes.

Since measurements of parallelly taken core samples at the same positions show no presence of oxygen in the hypolimnion, it is expected to find all oxygen concentrations in the recovered DPS around $0 \mathrm{mg} \mathrm{L}^{-1}$ as it can be

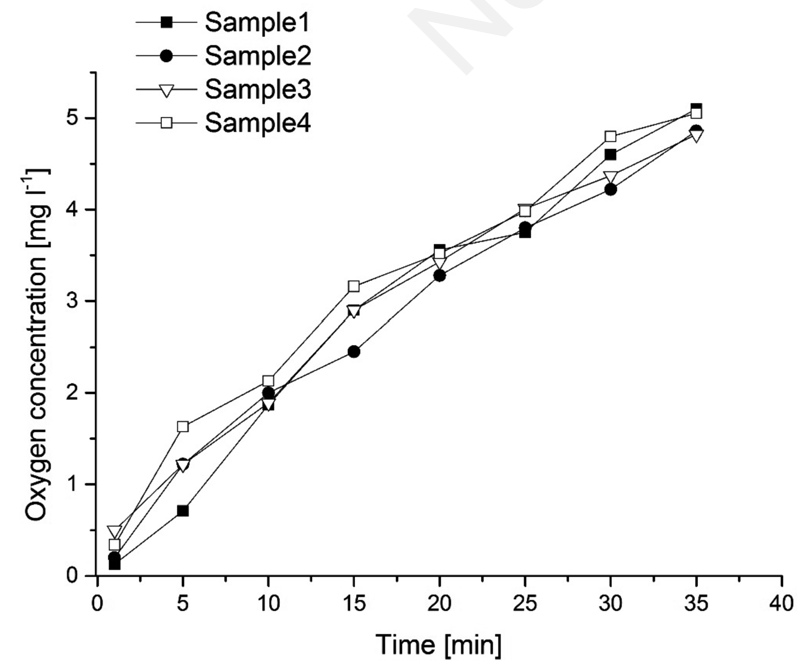

Fig. 4. Oxygen diffusion test showing back diffusion over time, measured simultaneously at four different membrane bags. expected in the hypolimnion of stratified lakes (Uhlmann and Horn, 2001). This leads to the assumption that all higher oxygen concentrations in the upper DPS chambers are due to post-recovery diffusion. Peeper II (black dots) shows a steep increase between 38 and $34 \mathrm{~cm}$ (Fig. 5, arrow). Due to a power supply problem, the oxygen measurement of this DPS was delayed for 25 min between chamber eight and nine (from the top), respectively $34 \mathrm{~cm}$ and $38 \mathrm{~cm}$, resulting in the depicted concentration increase of roughly $3.7 \mathrm{mg} \mathrm{L}^{-1}$ from one chamber to the next. Taking into account the results of the lower five to six chambers, the assumption suggests itself that the diffusion is initially delayed by clogging of the membrane, but resumes near-normal diffusion patterns after 10-15 min. It remains unclear how far the in situ concentrations of oxygen are affected by diffusion in the case of exposure to air as they may vary with the residual permeability of the membrane.

To minimize the effect of oxygen diffusion, it is recommended to change the order of measured chambers following the numbers in Fig. 6. In this manner, the important key values at maximum depth, directly below and above the SWI and in the free water could be measured with minimal bias. The rest of the chambers can be measured in normal order from the bottom to the top. To completely avoid oxygen diffusion, the peeper should be handled in inert atmosphere as suggested by some authors (Teasdale et al., 1995). However, this is linked to a big effort in equipment which was to be avoided during our measurements.

The question of the right duration of deployment was investigated by placing two DPS in the same position (3

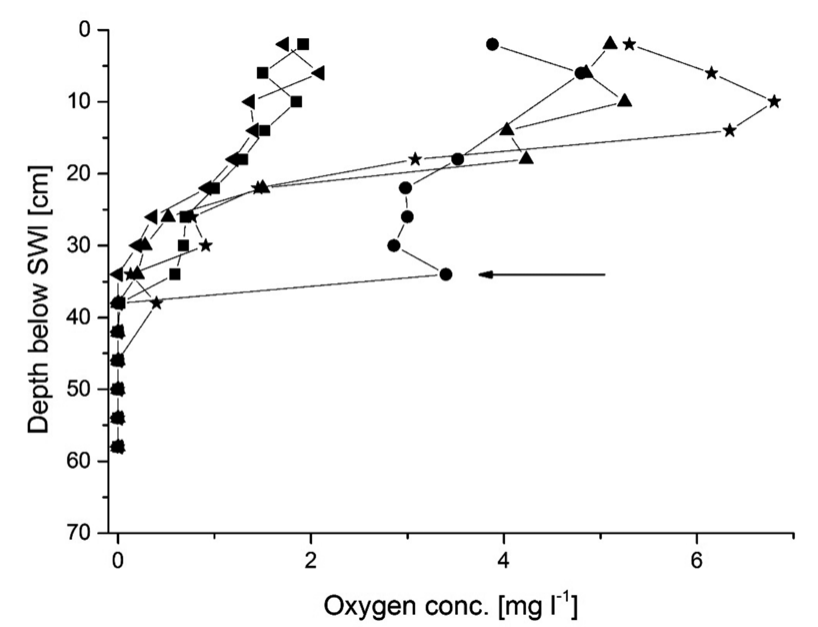

Fig. 5. Oxygen concentration in five dialysis pore water samplers after recovery, depicted over sediment depth. 


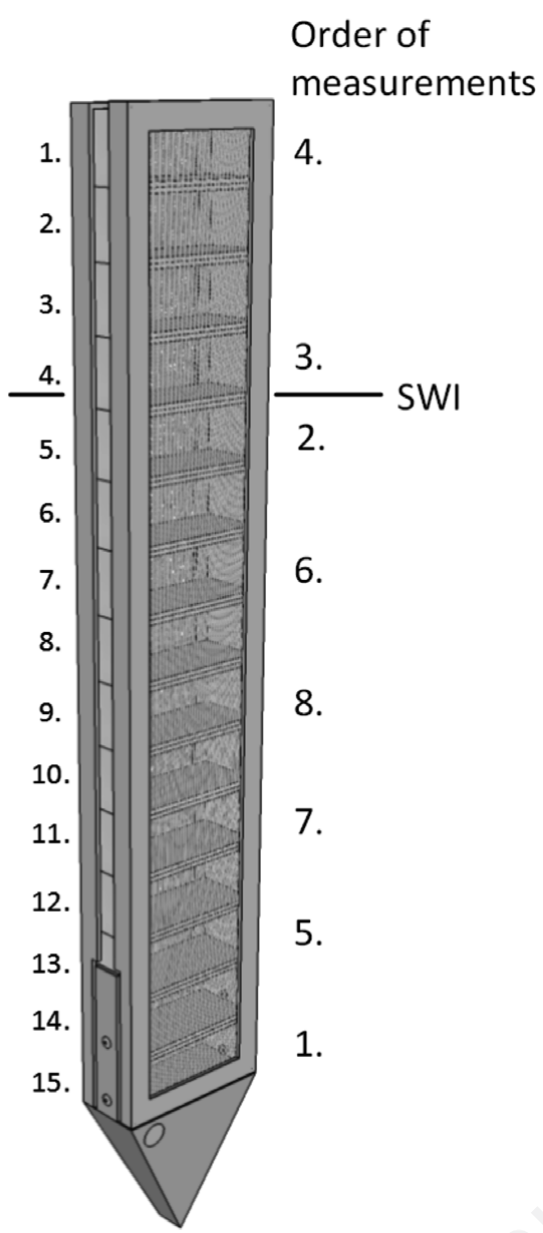

Fig. 6. Dialysis pore water sampler with recommended sampling order of the 15 chambers; design and construction by F. Gauger.

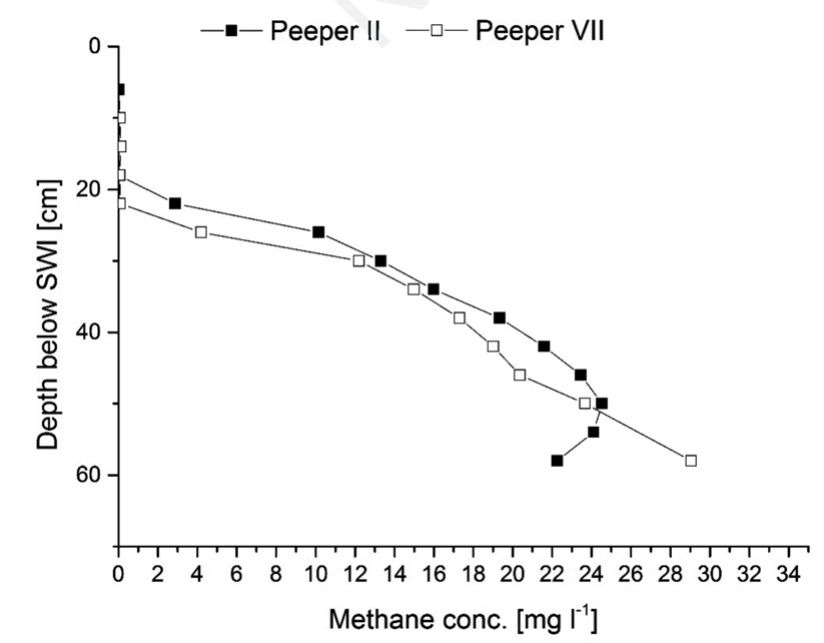

Fig. 7. Methane concentrations in two peepers resulting from different deployment times. $\mathrm{m}$ distance) at the same depth. The second DPS (Peeper VII) was deployed for $147 \mathrm{~h}$ and therefore $66 \mathrm{~h}$ after the first one (Peeper II, 213 hours) leading to the methane concentrations shown in Fig. 7. It is shown that the methane concentrations are nearly the same in both peepers, beside the slightly higher concentrations in the lower chambers in peeper VII, which was deployed even shorter. It can be stated that future deployment times can be reduced to six days. This is exemplarily confirmed since sulphate, which is considered to be the compound with the slowest diffusion rate, reaches higher concentrations at peeper VII (data not shown).

\section{CONCLUSIONS}

The new DPS placing system described in this manuscript is adapted for monitoring sediment pore water with more single DPS, therefore making it possible to survey a larger area of sediment with less effort. It makes the use of divers and submarines unnecessary and hence has the potential to reduce survey costs significantly. The DPSPS makes it possible to achieve precise placement of many DPS in one working day. The system was designed and tested in depth of $40 \mathrm{~m}$ but can surely be adapted to work until $80 \mathrm{~m}$ of water depth. The first results obtained were very promising but the on-board measurements can still be biased by back diffusion, depending on the measured compound. This paper gives recommendations for an optimized sampling procedure to reduce most of the bias and still prevail a simple sample treatment.

Due to the costs and general effort, the investigation of pore water in larger depth was limited. The DPSPS will allow a more detailed investigation of larger areas in the same time for lower costs. This deployment and measurement technique represents a valuable part in the future assessment of greenhouse gas emissions from surface water bodies.

\section{ACKNOWLEDGMENTS}

Many thanks go to the UFPR, DHS research team with Prof. Fernandes and Prof. Bleninger as well as the technical stuff of the DHS which supported the research activities. We also thank Dr. Rodrigo Moraes da Silveira and his team from the LACTEC Institute of Technology for Development for carrying out all the necessary laboratory work. Thanks to COPEL for allowing the measurements at the reservoir. We are indebted to the Baden-Württemberg Stiftung for the financial support of this research project by the Baden-WürttembergSTIPENDIUM - BWS plus.

\section{REFERENCES}

Bartram J, Richard B, 1996. Water quality monitoring - A prac- 
tical guide to the design and implementation of freshwater quality studies and monitoring programmes. E\&FN Spon, London: $160 \mathrm{pp}$.

Brandl H, Hanselmann KW, 1991. Evaluation and application of dialysis porewater samplers for microbiological studies at sediment-water interfaces. Aquat. Sci. 53:55-73.

Crank J, McFarlane NR, 1981. Diffusion processes in environmental systems. Macmillan, London: $160 \mathrm{pp}$.

Dattagupta S, Telesnicki G, Luley K, Predmore B, McGinley M, Fisher C, 2007. Submersible operated peepers for collecting pore water from deep-sea sediments. Limnol. Oceanogr.Meth. 5:263-268.

Hesslein R, 1976. An in situ sampler for close interval pore water studies. Limnol. Oceanogr. 21:912-914.

Jacobs PH, 2002. A new rechargeable dialysis pore water sampler for monitoring sub-aqueous in-situ sediment caps. Water Res. 36:3121-3129.

Lewandowski J, Casper P, Hupfer M, 2003. Small-scale horizontal heterogeneity of pore water phosphate in lakes. Ber. IGB 17:27-35.

Lewandowski J, Rüter K, Hupfer M, 2002. Two-dimensional small-scale variability of pore water phosphate in freshwater lakes: results from a novel dialysis sampler. Environ. Sci. Technol. 36:2039-2047.

Lyons, WB, Gaudette HE, Smith GM, 1979. Pore water sampling in anoxic carbonate sediments: oxidation artefacts. Nature 277:48-49.

Schubert CJ, Vazquez F, Lösekann-Behrens T, Knittel K, Tonolla M, Boetius A, 2011. Evidence for anaerobic oxidation of methane in sediments of a freshwater system (Lago di Cadagno). FEMS Microbiol. Ecol. 76:26-38.

Teasdale PR, Batley GE, Apte SC, Webster IT, 1995. Pore water sampling with sediment peepers. Trends Anal. Chem. 14: 250-256.

Thomas B, Arthur MA, 2010. Correcting porewater concentration measurements from peepers: Application of a reverse tracer. Limnol. Oceanogr.-Meth. 8:403-413.

Uhlmann D, Horn W, 2001. [Hydrobiologie der Binnengewässer].[Article in German]. UTB Stuttgart 3:124-125.

Urban NR, Dinkel C, Wehrli B, 1997. Solute transfer across the sediment surface of a eutrophic lake. I. Porewater profiles from dialysis samplers. Aquat. Sci. 59:1-25.

Winfrey MR, Zeikus JG, 1977. Effect of sulfate on carbon and electron flow during microbial methanogenesis in freshwater sediments. Appl. Environ. Microbiol. 33:275-281. 